\title{
Skin of the Extremity
}

National Cancer Institute

\section{Source}

National Cancer Institute. Skin of the Extremity. NCI Thesaurus. Code C53276.

The integumentary covering of the upper and lower extremities. 